\title{
Front End Support Systems for the Advanced Photon Source*
}

\author{
J. Barraza, D. Shu, and T.M. Kuzay \\ Advanced Photon Source \\ Argonne National Laboratory \\ 9700 South Cass Avenue \\ Argonne, IL 60439
}

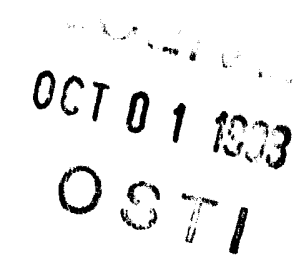

The support system designs for the Advanced Photon Source (APS) front ends are complete and will be installed in 1994. These designs satisfy the positioning and alignment requirements of the front end components installed inside the storage ring tunnel, including the photon beam position monitors, fixed masks, photon and safety shutters, filters, windows, and differential pumps. Other components include beam transport pipes and ion pumps. The designs comprise 3-point kinematic mounts and single axis supports to satisfy various multi-direction positioning requirements from course to ultra-precise. The confined space inside the storage ring tunnel has posed engineering challenges in the design of these devices, considering some components weigh as much as $500 \mathrm{~kg}$. These challenges include designing for mobility during commissioning and initial alignment, mechanical and thermal stability, and precise lowprofile vertical and horizontal positioning. As a result, novel stages and kinematic mounts have emerged with modular and standard designs. This paper will discuss the diverse group of support systems, including specifications and performance data of the prototypes.

* Supported by the U.S. Department of Energy BES Materials Science under Contract No. W-31-109-ENG-38 


\section{Introduction}

Located inside the storage ring tunnel, the front ends perform various precision photon beam tailoring, position monitoring, and shuttering functions [1]. To achieve proper performance of the front ends, the components must be positioned and supported with high precision, because the designs permit small tolerance errors to allow the photon beam to pass through. Vacuum chambers will introduce thermal expansions during baking and normal operations, which may overconstrain the chambers or precision mechanical devices. Additionally, rapid shuttering functions can introduce vibrations to other components. The solutions presented here utilize 3-point kinematic mounts which provide maximum stability and motion without overconstraint. Also presented here is the photon beam position monitor (PBPM) support, critical for calibration and absolute position determination.

The floor space provided for the front end components is approximately $1 \mathrm{~m}$ wide with access via a $1.422 \mathrm{~m}$ door. This places dimensional constraints on the components and support systems for installation, alignment, and future maintenance requirements. As a result, narrow supports were designed to a maximum width of $485 \mathrm{~mm}$. The photon beam elevation of $1.4 \mathrm{~m}$ places a height constraint on the support systems of $1.2 \mathrm{~m}$, excluding the PBPMs. This standardizes and economizes the support systems and also eases aligning efforts by using a fixed-height mounting plate as a reference for measuring coordinates.

\section{Specifications}

Table 1 summarizes the range of support systems designed for the APS front ends. Figure 1 illustrates the "cone-flat-v" 3-point kinematic mount concept as applied to the standard and precision style of stages for achieving five degrees-of-freedom motion. This concept provides the advantages of 3-point stability, reduced space consumption, minimum number of motor drives, free and unconstrained thermal expansion, and 
position repeatability after disassembly, satisfying the specifications for supporting front end components.

The PBPM specifies the highest performance demands in the three required motions: vertical, horizontal, and rotational translation. To successfully implement beam position calibration, the low-profile vertical [2] and horizontal rolling positioning stages are designed with submicron sensitivity, corresponding to the spatial resolution requirements of the PBPMs [3]. The rotation stage functions to optimize the blade signal output and minimize thermal loading. Thermal stability is also an important requirement of the PBPM support system. Small temperature fluctuations in the storage ring tunnel can cause thermal expansions in typical structural metals up to two orders of magnitude greater than the PBPM sensitivity.

The 32 front ends to be installed in 1994 will require over 400 supports, dictating standard and modular designs for economic benefits.

\section{Mechanical Designs}

Figure 2 shows a typical standard kinematic mount support system consisting of seven elements. The basic support frame (1) features removable cross beams for component access and leveling pads for stability. Stability concerns were addressed by finite element models, which calculated a lowest-mode frequency of $45 \mathrm{~Hz}$ under a 500 $\mathrm{kg}$ mass load. The storage ring basemat has the low frequency/low amplitude characteristics to avoid resonance with the frame.

Motions are accomplished by the translation slides on the frame. Horizontal adjustments are accomplished with two commercial dovetail machine slides (2). Three vertical translation slides (3) provide vertical adjustment. As shown in Figure 3, their design consists of a commercial worm-gear actuator, which lifts a frame guided by a precision-bearing rail. A mechanical counter provides absolute position information, and the position can be locked by a flexible hand-knob clamp. Kinematic freedom is obtained 
by the "cone" (4), "V-groove" (5), and "flat" (6) couplings affixed to the vertical slides (details are shown in Figure 4). The component mounting plate (7) supports the front end component and provides for miscellaneous fixtures and aligning fiducials at a standard $1.2 \mathrm{~m}$ elevation.

Figure 5 shows the precision kinematic mount support system consisting of the basic support frame (1), three low-profile vertical stages (2) [1], a single-axis drive horizontal stage (3), a single-axis drive/free rolling combination horizontal stage (4), a 2-axis free rolling horizontal slide (5), 3 "cone" couplings (6) from the standard design, and the component mounting plate (7). Kinematic mount freedom is simulated by the vertical/horizontal stages combination: the "cone" is formed by the (2)-(3) stage combination; the "V-groove" by the (2)-(4) stage combination; and the "flat" by the (2)(5) stage combination. Figure 6 shows an example of these precision stages used in a beamline experimental support table.

As shown in Figure 7, the PBPM support system consists of four elements. The support column (1) provides rigidity and thermal stability by using a large steel cylinder filled with silica sand and wrapped in a ceramic cloth. This economical design yields thermal stability by delaying the thermal response of the column to ambient air temperature changes while providing high frequency vibration isolation. The stepper motor-driven, low-profile vertical stage (2) utilizes a preloaded housing to provide precise rolling motion and a special spherical coupling that prevents rotation of the lifting screw. A high gear ratio obtains the submicron resolution.. The horizontal positioning stage (3) and rotation stage (4) also emphasize low profile designs to minimize thermal expansion. Thermal stability is further increased by wrapping the stages assembly in ceramic cloth.

The single column supports are the simplest supports used for beam pipes, small ion pumps, etc. Figure 8 shows an example consisting of a support pipe (1), adjusting screw (2), support frame (3), sliding pins (4), and the clamping assembly (5). Its main 
function is to allow the beam pipe to expand freely and maintain support during large temperature changes.

\section{Stage Prototypes}

The support systems prototyped include the precision kinematic mount stages and the PBPM translation and rotation stages. The stages were tested using a Laser Doppler Displacement Meter (LDDM) with a $0.01-\mu \mathrm{m}$ sensitivity for precision measurement. Sensitivity tests were performed by incrementing each stage stepwise at 400 steps per motor revolution without closed-loop feedback. The precision kinematic mount stages were incrementally moved a distance of $50 \mu \mathrm{m}$. As plotted in Figure 9, the vertical stage sensitivity is approximately $1.67 \mu \mathrm{m}$. The horizontal stage achieved a sensitivity of 2.50 $\mu \mathrm{m}$. Similarly, Figure 10 shows that the PBPM vertical stage has a 0.1 to $0.2-\mu \mathrm{m}$ sensitivity when moved over a $12.5 \mu \mathrm{m}$ distance. The PBPM horizontal stage equally achieved the same sensitivity. Repeatability tests were performed by moving the stages through 100 cycles. Results show that a $25-\mu \mathrm{m}$ position repeatability is achieved by the precision kinematic mount stages while supporting loads up to $453 \mathrm{~kg}$. The PBPM stages show a less than $2-\mu \mathrm{m}$ position repeatability while supporting loads up to $90 \mathrm{~g}$.

\section{Summary}

We have presented a general overview of the designs used for the APS front end supports. Principally, positioning stage designs used in 3-point kinematic mount fashion were developed to operate in the confined space of the storage ring tunnel. Highprecision stages and a thermally stable support column were also developed to meet the PBPM submicron sensitivity requirements. Performance measurements show that the stages satisfy the front end support requirements. Single column supports were designed for miscellaneous components not requiring precision or kinematic motion. Due to the 
large number of supports required, standard and modular designs emerged, resulting in economical designs that may be used in other applications at the APS.

\section{Acknowledgments}

Our appreciation goes to our summer student, Patrick Wei, who has done excellent work developing software to manipulate our support systems and also provided valuable assistance in obtaining test data. Analytical work was carried out by Zhibi Wang of the APS.

\section{References}

[1] D. Shu, J. Barraza, T. Sanchez, R.W. Nielson, J.T. Collins and T.M. Kuzay, "Front End Designs of the $7 \mathrm{GeV}$ Advanced Photon Source," Nucl. Instr. and Meth. A319 (1992) 63.

[2] Patent Applied for APS/ANL, May 1991.

[3] D. Shu, B. Rodricks, J. Barraza, T. Sanchez, and T.M. Kuzay, "The APS X-ray Undulator photon Beam Position Monitor and Tests at CHESS and NSLS," Nucl. Instr. and Meth. A319 (1992) 56.

\section{DISCLAIMER}

This report was prepared as an account of work sponsored by an agency of the United States Government. Neither the United States Government nor any agency thereof, nor any of their employees, makes any warranty, express or implied, or assumes any legal liability or responsibility for the accuracy, completeness, or usefulness of any information, apparatus, product, or process disclosed, or represents that its use would not infringe privately owned rights. Reference herein to any specific commercial product, process, or service by trade name, trademark, manufacturer, or otherwise does not necessarily constitute or imply its endorsement, recommendation, or favoring by the United States Government or any agency thereof. The views and opinions of authors expressed herein do not necessarily state or reflect those of the United States Government or any agency thereof. 


\section{Figure Captions}

1. 3-Point Kinematic Mounting

2. APS Front End Standard Kinematic Mount Support System. (1) Support Frame, (2) Dovetail Slide, (3) Vertical Positioning Slide, (4) Cone, (5) V-Groove, (6) Flat Kinematic Mounts, (7) Component Mounting Plate.

3. Standard Vertical Positioning Slide.

4. Kinematic Mounts Used in the Standard Kinematic Mount Support System.

5. APS Front End Precision Kinematic Mount Support System. (1) Support Frame, (2) Vertical Positioning Stage, (3) Single-Axis Drive Horizontal Stage, (4) Single-Axis Drive/Free Rolling Combination Horizontal Stage, (5) 2-Axis Free Rolling Horizontal Slide, (6) Cone Coupling, (7) Component Mounting Plate.

6. Precision Kinematic Mount Stages used in a beamline experiment support table.

7. APS PBPM support system. (1) Support Column, (2) Vertical Positioning Stage, (3) Horizontal Stage, (4) Rotation Stage.

8. APS Front End Beam Pipe Support consisting of (1) Support Pipe, (2) Lifting Screw, (3) Support Frame, (4) Sliding Pins, and (5) Clamping assembly.

9. Sensitivity measurement for the Precision Kinematic Mount vertical stage showing approximately a $1.67-\mu \mathrm{m}$ sensitivity. The measuring device was a Laser Doppler Displacement Meter with a $0.01-\mu \mathrm{m}$ sensitivity.

10. Sensitivity measurement for the PBPM vertical stage showing approximately a 0.1 to $0.2-\mu \mathrm{m}$ step size. The measuring device was a Laser Doppler Displacement Meter with a $0.01-\mu \mathrm{m}$ sensitivity. 
Table 1

APS Front End Support Systems Specifications

\begin{tabular}{|c|c|c|c|c|}
\hline Characteristic & $\begin{array}{l}\text { Standard } \\
\text { Kinematic } \\
\text { Mounts }\end{array}$ & $\begin{array}{l}\text { Precision } \\
\text { Kinematic } \\
\text { Mounts }\end{array}$ & $\begin{array}{l}\text { PBPM Support } \\
\text { Stages }\end{array}$ & $\begin{array}{l}\text { Single } \\
\text { Pipe } \\
\text { Supports }\end{array}$ \\
\hline Maximum Load, $\mathrm{Kg}$ & 1000 & 1000 & 90 & 90 \\
\hline Slide Type (Vertical) & Linear Rolling & Linear Rolling & Linear Rolling & N/A \\
\hline Slide Type (Horizontal) & $\begin{array}{l}\text { Regular } \\
\text { Friction } \\
\end{array}$ & Linear Rolling & Linear Rolling & N/A \\
\hline $\begin{array}{l}\text { Travel Range, mm } \\
\text { (Vertical \& Horizontal) }\end{array}$ & 50 & 12.7 & 12.7 & 50 \\
\hline $\begin{array}{l}\text { Motion Resolution, } \mu \mathrm{m} \\
\text { (Vertical) }\end{array}$ & 50 & 10 & 0.1 & N/A \\
\hline $\begin{array}{l}\text { Motion Resolution, } \mu \mathrm{m} \\
\text { (Horizontal) }\end{array}$ & 50 & 10 & 0.1 & N/A \\
\hline $\begin{array}{l}\text { Motion Repeatability, } \\
\mu \mathrm{m} \text { (Vertical) }\end{array}$ & 100 & 50 & 2 & N/A \\
\hline $\begin{array}{l}\text { Motion Repeatability, } \\
\mu \mathrm{m} \text { (Horizontal) }\end{array}$ & 250 & 50 & 2 & N/A \\
\hline $\begin{array}{l}\text { Straightness of } \\
\text { Trajectory, rad } / 25 \mathrm{~mm} \\
\text { (Vertical) }\end{array}$ & $5 \mathrm{E}-4$ & $2 \mathrm{E}-4$ & $1 \mathrm{E}-5$ & N/A \\
\hline $\begin{array}{l}\text { Straightness of } \\
\text { Trajectory, rad/25mm } \\
\text { (Horizontal) }\end{array}$ & $2 \mathrm{E}-3$ & $1 \mathrm{E}-4$ & $1 \mathrm{E}-5$ & N/A \\
\hline Basic Operating Mode & Manual & Stepping Motor & Stepping Motor & Manual \\
\hline $\begin{array}{l}\text { Optional Operating } \\
\text { Mode }\end{array}$ & Stepping Motor & Manual & Manual & N/A \\
\hline
\end{tabular}




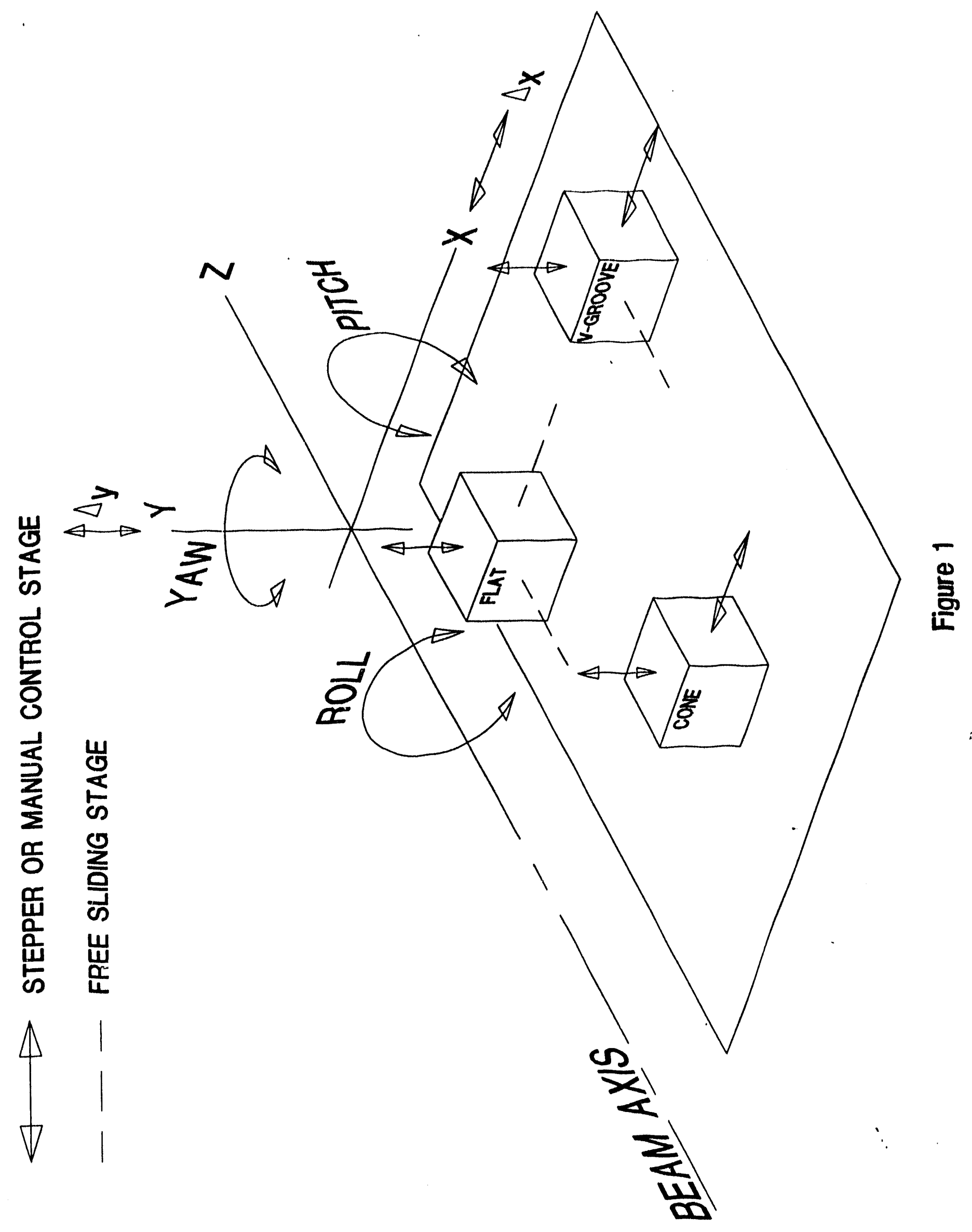



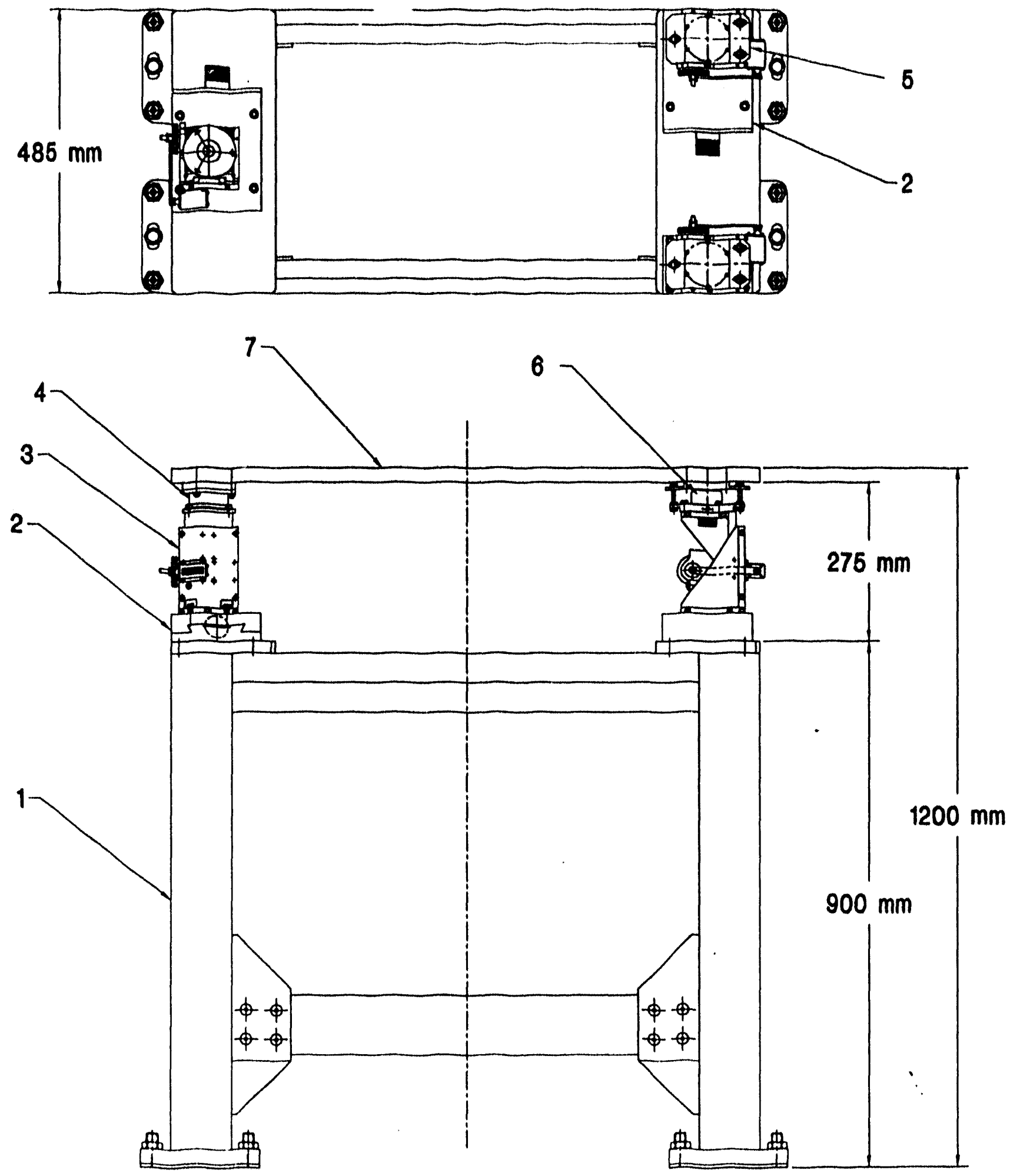

Figure 2 


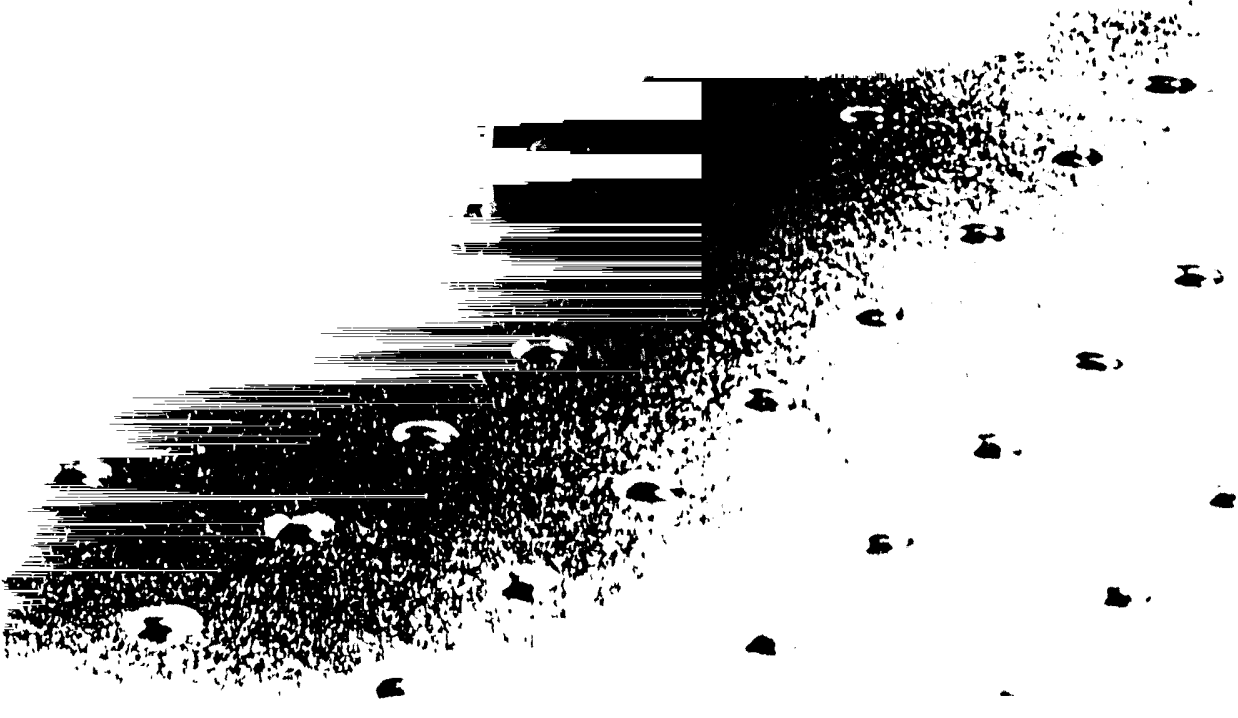




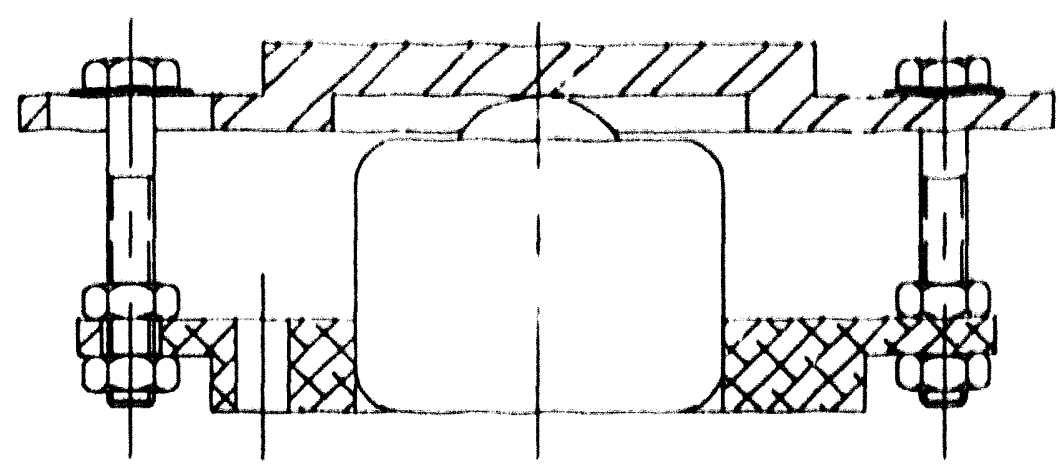

KINEMATIC MOUNT FLAT

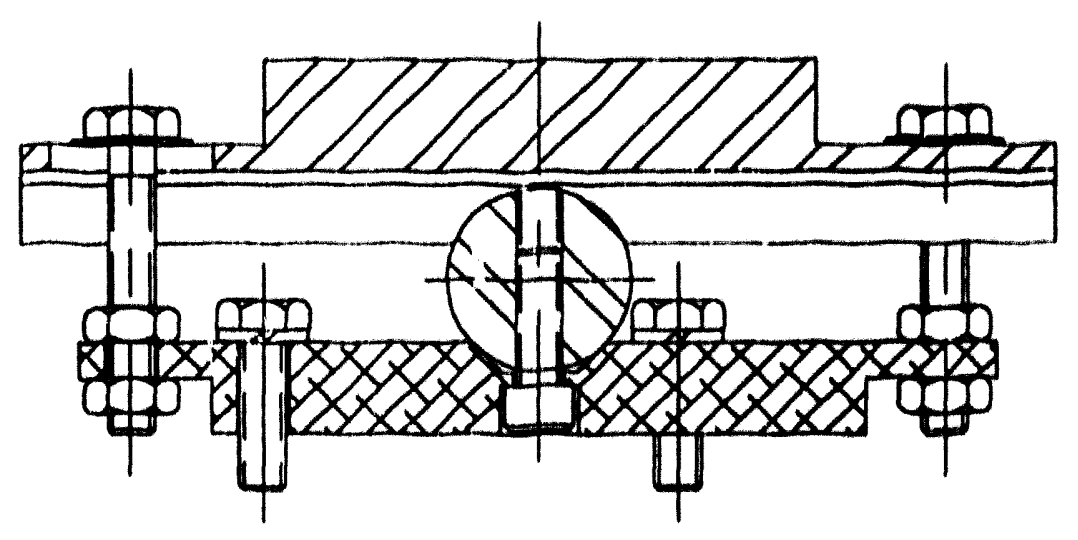

KINEMATIC MOUNT V-GROOVE

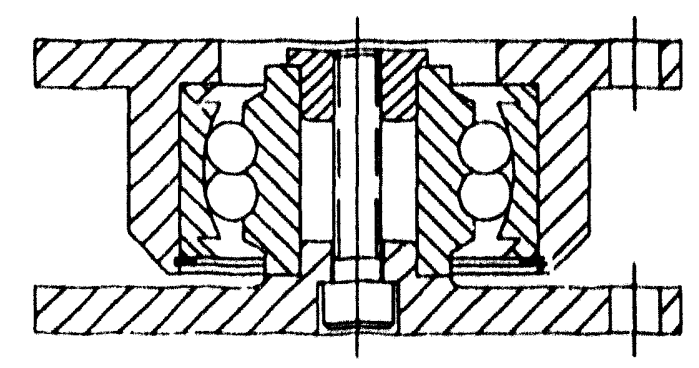

KINEMATIC MOUNT CONE

Figure 4 

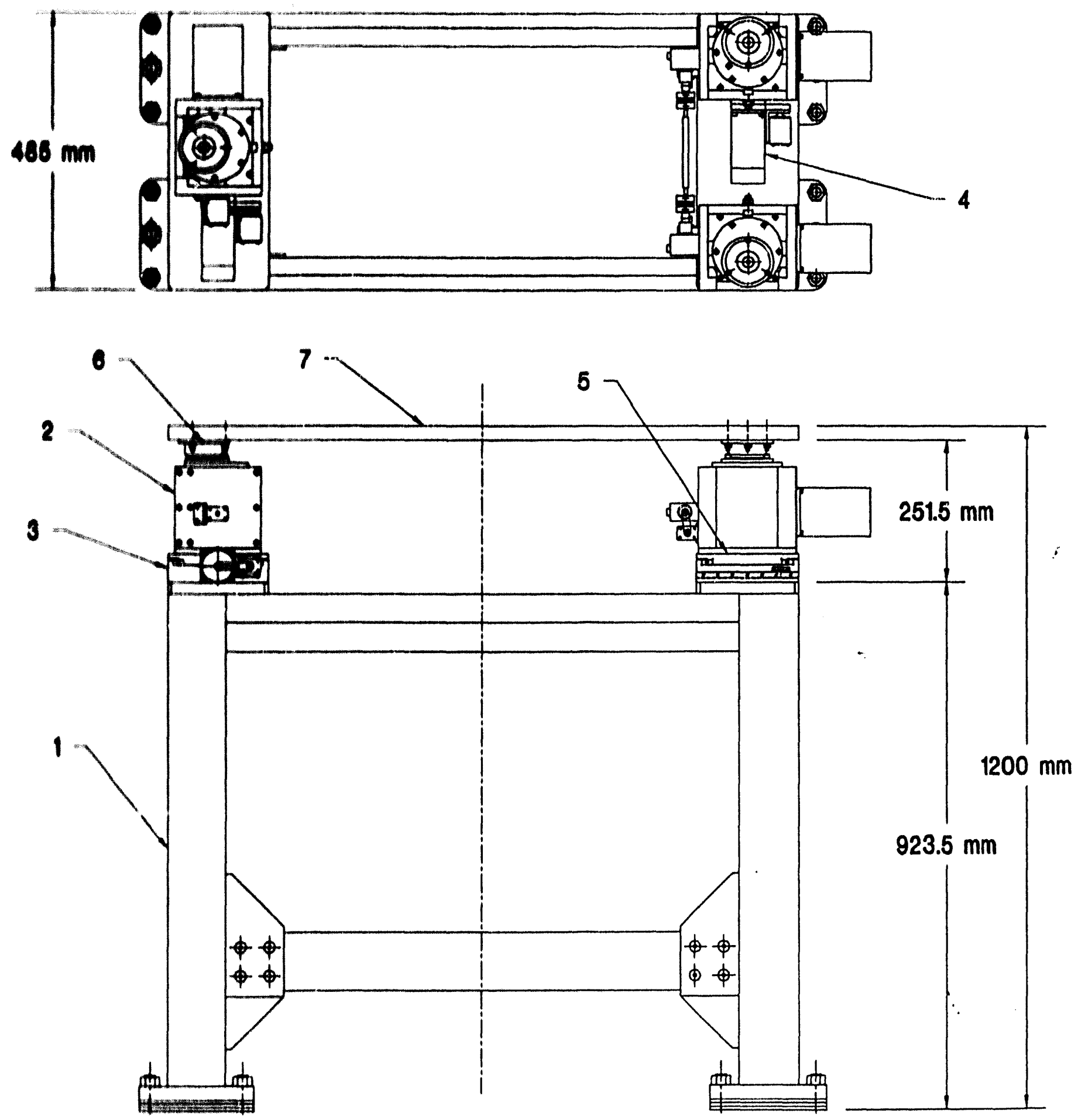

Figure 5 


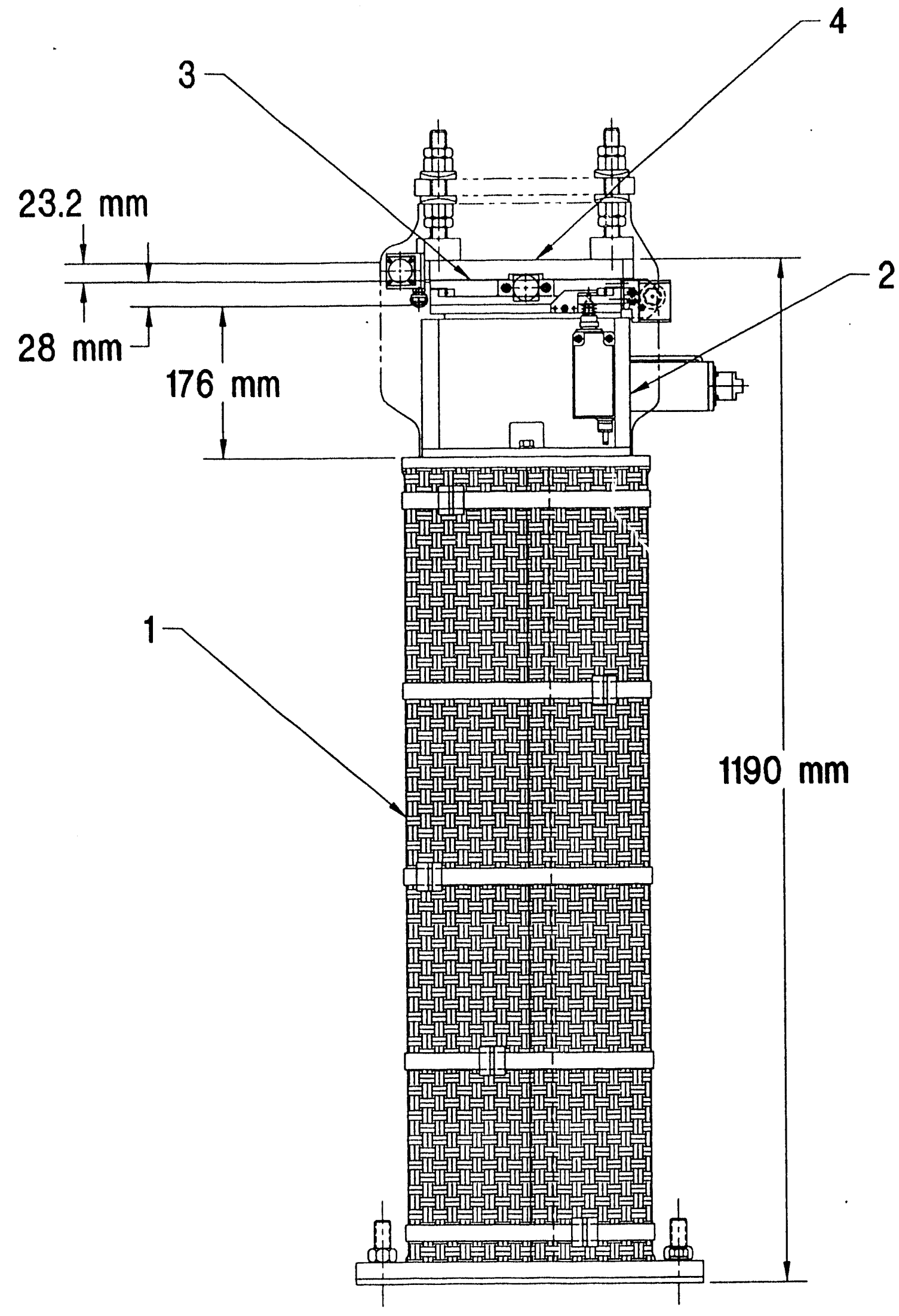

Figure 7 


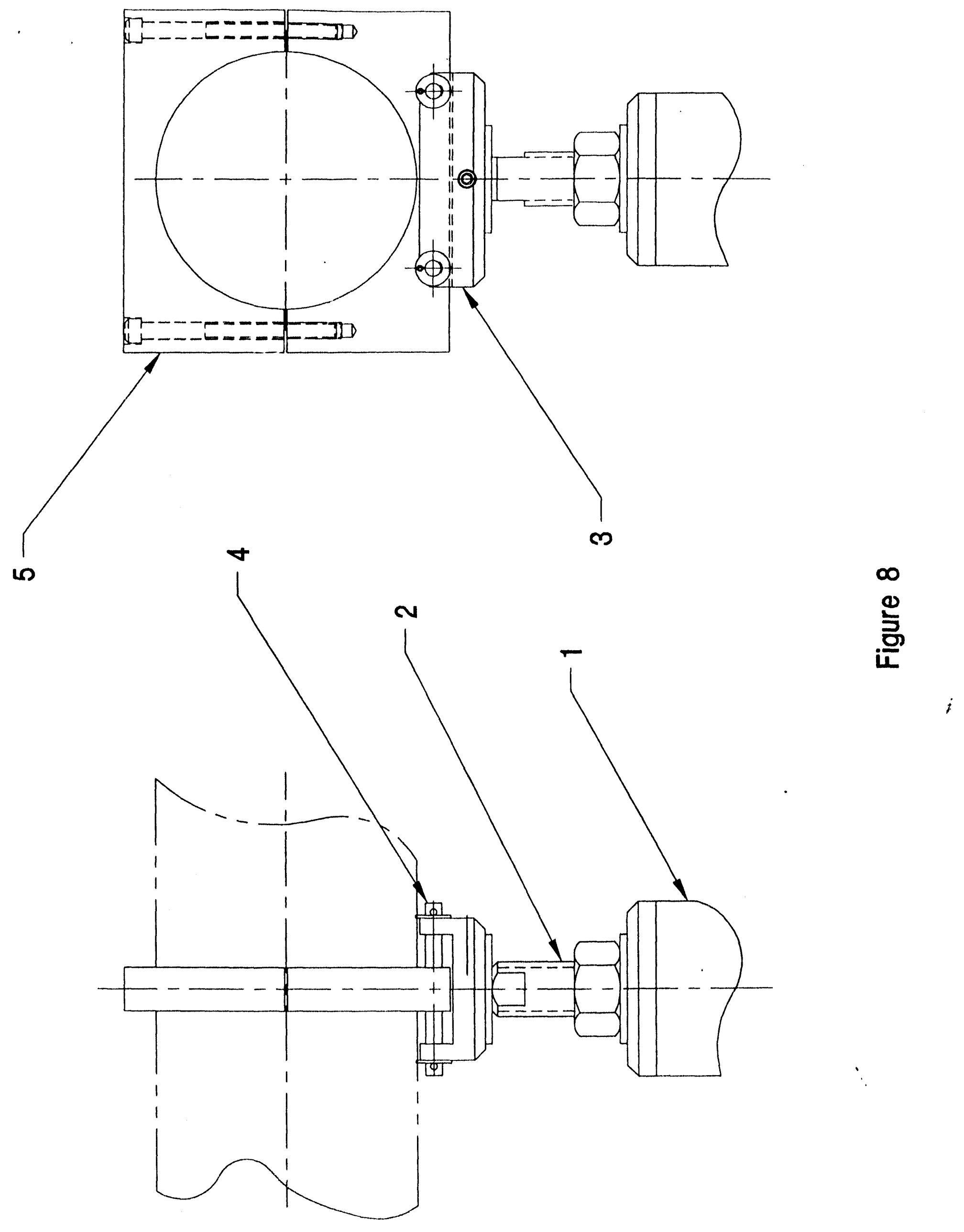




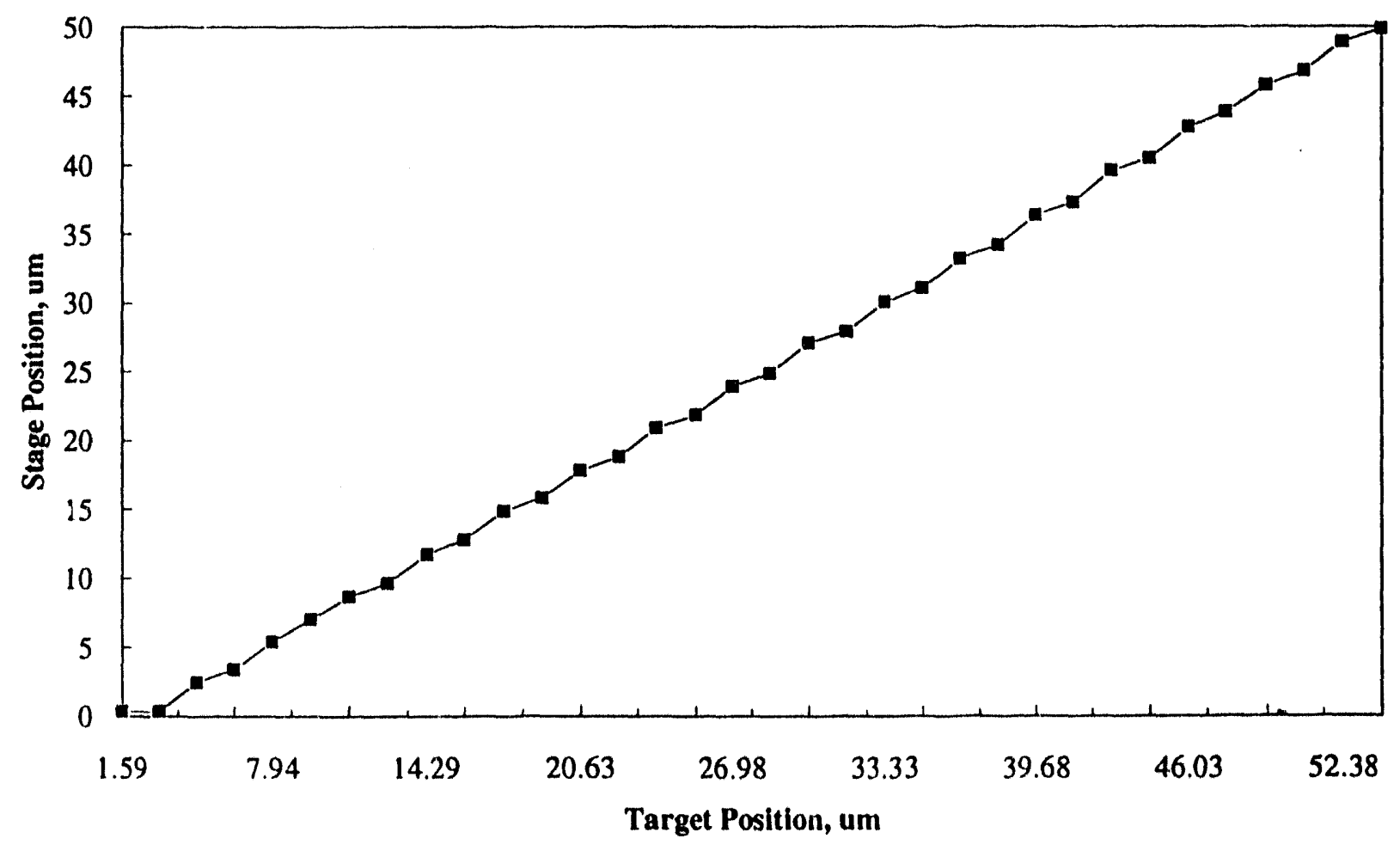

Figure 9 


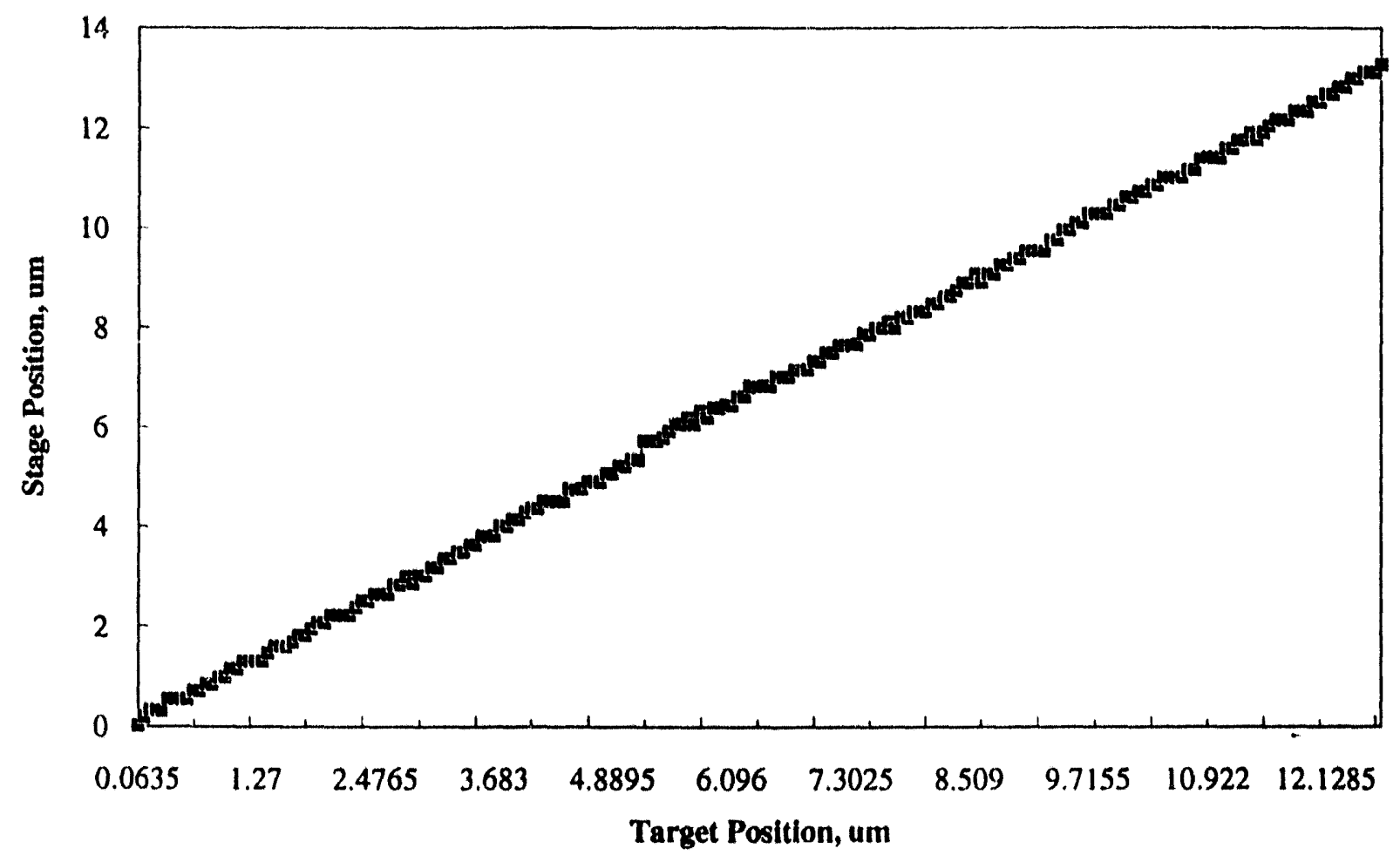

Figure 10 

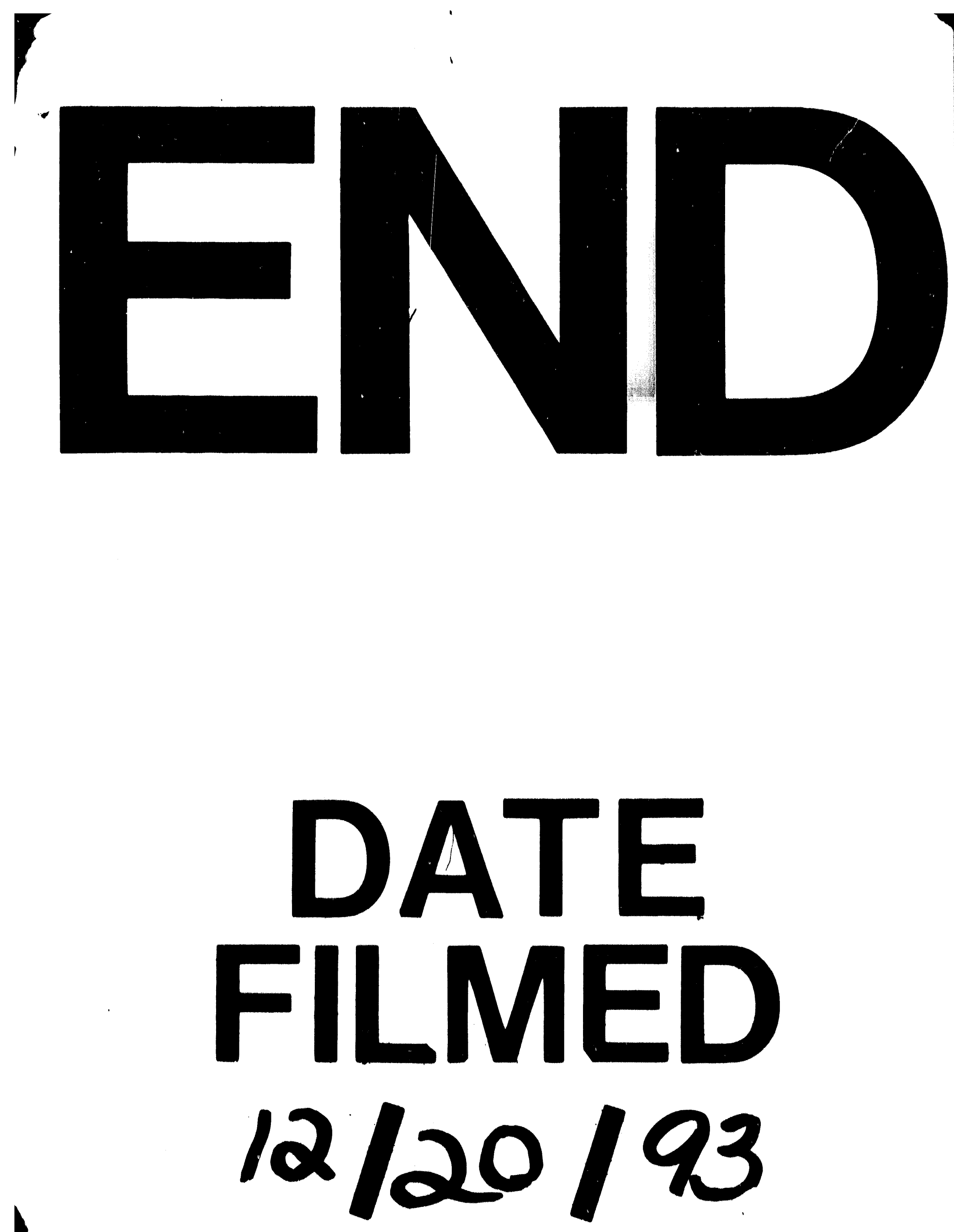
